\title{
Correction to: EMF 35 JMIP study for Japan's long-term climate and energy policy: scenario designs and key findings
}

\author{
Masahiro Sugiyama ${ }^{1}\left(\mathbb{D} \cdot\right.$ Shinichiro Fujimori ${ }^{2,3,10} \cdot$ Kenichi Wada $^{4} \cdot$ Ken Oshiro $^{2}$ - Etsushi Kato ${ }^{5}$ (D)

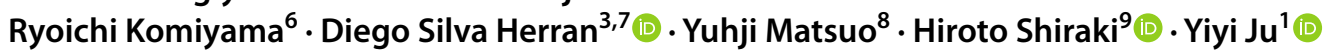

Published online: 26 June 2021

(c) The Author(s) 2021

\section{Correction to: Sustainability Science (2021) 16:355-374 https://doi.org/10.1007/s11625-021-00913-2}

In the original publication of the article, data availability was missing and it is provided in this correction.

The scenario data is available at https://doi.org/10.5281/ zenodo.4817656.

Open Access This article is licensed under a Creative Commons Attribution 4.0 International License, which permits use, sharing, adaptation, distribution and reproduction in any medium or format, as long as you give appropriate credit to the original author(s) and the source, provide a link to the Creative Commons licence, and indicate if changes were made. The images or other third party material in this article are included in the article's Creative Commons licence, unless indicated otherwise in a credit line to the material. If material is not included in the article's Creative Commons licence and your intended use is not permitted by statutory regulation or exceeds the permitted use, you will need to obtain permission directly from the copyright holder. To view a copy of this licence, visit http://creativecommons.org/licenses/by/4.0/.
Publisher's Note Springer Nature remains neutral with regard to jurisdictional claims in published maps and institutional affiliations.

The original article can be found online at https://doi.org/10.1007/ s11625-021-00913-2.

Masahiro Sugiyama

masahiro_sugiyama@alum.mit.edu;

masahiro@ifi.u-tokyo.ac.jp

1 Institute for Future Initiatives, The University of Tokyo, 7-3-1 Hongo, Bunkyo-ku, Tokyo 113-0033, Japan

2 Graduate School of Engineering, Kyoto University, Kyoto daigaku-katsura, Nishikyo-ku, Kyoto 615-8530, Japan

3 National Institute for Environmental Studies, 16-2 Onogawa, Tsukuba, Ibaraki 305-8506, Japan

4 Research Institute of Innovative Technology for the Earth, 9-2 Kizugawadai, Kizugawa, Kyoto 619-0292, Japan

5 Institute of Applied Energy, 1-14-2 Nishi-Shimbashi, Minato, Tokyo 105-0003, Japan
6 School of Engineering, The University of Tokyo, Hongo 7-3-1, Bunkyo-ku, Tokyo 113-8656, Japan

7 Institute for Global Environmental Strategies (IGES), 2108-11 Kamiyamaguchi, Hayama, Kanagawa 240-0115, Japan

8 Institute of Energy Economics, Japan, Kachidoki 1-chome, Chuo-ku, Tokyo 104-0054, Japan

9 The University of Shiga Prefecture, 2500, Hassaka-cho, Hikone-City, Shiga 522-8533, Japan

10 International Institute for Applied System Analysis (IIASA), Schlossplatz 1, 2361 Laxenburg, Austria 